\title{
FARMAKOKINETIKA DAN BIOAVAILABILITY SENYAWA GOLONGAN SANTON REVIEW KOMPREHENSIF
}

\author{
Meri Susanti ${ }^{1^{*}}$ \\ ${ }^{1 *}$ Program Studi S3 Ilmu Kimia. Fakultas Matematika dan Ilmu Pengetahuan Alam \\ Universitas Andalas \\ $1^{*}$ e-mail : Meri susanti008@yahoo.com
}

\begin{abstract}
ABSTRAK
Pengobatan menggunakan obat herbal merupakan bentuk pengobatan tertua dan paling banyak digunakan dalam mengatasi masalah kesehatan. Pembuktian dasar farmakologis dalam penjaminan khasiat obat herbal masih menjadi tantangan sampai saat sekarang ini. Point yang tak kalah menarik adalah pertanyaan tentang bioavailabilitas untuk menilai sejauh mana dan seberapa cepat komponen aktif diserap setelah pemberian obat herbal. Selain itu dibutuhkan juga penjelasan tentang jalur metabolisme, serta penilaian rute eliminasi dan kinetika lainnya. Data ini sangat diperlukan untuk menghubungkan data uji farmakologis dengan efek klinis. Oleh karena itu sangat penting untuk memiliki pengetahuan tentang sifat farmakokinetika dari senyawa aktif setiap obat herbal. Untuk menggambarkan absorpsi, distribusi, metabolisme dan eksresi (ADME) dari beberapa senyawa golongan santon, tulisan ini merevew profil farmakokinetika 7 senyawa santon yang dipublikasi mulai tahun 2009 sampai sekarang.
\end{abstract}

Kata kunci; bioavailavility. Santon, farmakokinetika

\section{ABSTRACT}

The use of herbs for treating various ailment dates back several centuries. Evidence-based verification of the efficacy of Herbal medicines is still frequently lacking. Of particular interest is the question of bioavailability to assess to what degree and how fast compounds are absorbed after administration of herbal. Of further interest is the elucidation of metabolic pathways, and the assessment of elimination routes and their kinetics. These data become an important issue to link data from pharmacological assays and clinical effects. A better understanding of the pharmacokinetics and bioavailability of phytopharmaceuticals can also help in designing rational dosage regimens. To provide provide a detailed picture on ADME parameters (absorption, distribution, metabolism, and excretion) of some xanthone active compound, this article reviews the pharmacokinetic profile of 7 xanthones bioactive compound from the year 2009 onward.

Keyword : Bioavailability, Xanthone, Pharmacokinetic

\section{PENDAHULUAN}

Santon adalah senyawa organik golongan polifenol dengan rumus molekul $\mathrm{C}_{13} \mathrm{H}_{8} \mathrm{O}_{2}$ yang ditemukan pertama kali pada fungi dan saat sekarang banyak diisolasi dari berbagai organ tumbuhan berbunga (angiospermae) dari kelas dikotiledone terutama dari family Gentianaceae (Ghosal et al. 1973), Gutiferae (Bennet et al. 1989), Rubiaceaea (Talamond et al. 2008), Moraceae (Ee et al. 2011), Polygalaceae (Tizziani et al. 2018) dan Anacardiaceae (Morais et al. 2012) . Kerangka dibenzo- $\gamma$-piron yang terdapat pada struktur intinya memainkan peran penting dalam aktivitas biologis golongan senyawa ini (Mazimba et al. 2013). Aktivitas beragam dari derivate santon dipengaruhi oleh substitusi gugus fungsi pada kerangka trisikliknya (Jiang et al. 2004). Santon telah dilaporkan memiliki aktivitas farmakologi yang baik sebagai antiinflamasi (Mohan et al. 2018; Tewtrakul et al. 2009), antibakteri (Iimuna et al. 1996; Dharmaratne et al. 2013; Suzy et al. 2018), antijamur (Kaomongkolgit et al. 2009), antivirus (Hu et al. 2019), antidiabetes (Miura et al. 2001; Nelli et al. 2013; Sriyatep et al. 2015 and Trinh et al. 2017), antikanker (Akao et al. 2008; Shan et al. 2011; Orozko et al. 2013; Victor et al. 2014, Zhengxiang et al. 2015 and Wahyuni et al. 2015 and Ganogpichayagrai et al. 2017), antitrombolitik (Yoo et al. 2014), antiplatelet (Jantan et al, 2002) dan antikolesterol (Dachriyanus et al, 2006).
Aktivitas yang sangat baik dari senyawa santon telah mendorong pemanfaatan tumbuhan yang mengandung senyawa ini dalam pengobatan berbagai penyakit. Peningkatan informasi evaluasi terapeutik dan toksisitas dari senyawa santon juga telah menjadi salah satu alasan peningkatan pemanfaatan tumbuhan dengan kandungan santon akhir-akhir ini. Kemajuan dalam teknologi analisis telah banyak menyumbang dalam penemuan derivate santon aktif yang bertanggung jawab dalam terapi.

Pembuktian dasar farmakologis dalam penjaminan khasiat obat berbasis tumbuhan masih tetap menjadi tantangan sampai saat sekarang ini. Point yang tak kalah menarik adalah pertanyaan tentang bioavailabilitas untuk menilai sejauh mana dan seberapa cepat komponen aktif diserap setelah pemberian obat herbal. Selain itu dibutuhkan juga penjelasan tentang jalur metabolisme (menghasilkan senyawa aktif baru yang berpotensi), serta penilaian rute eliminasi dan kinetika lainnya. Data ini sangat diperlukan untuk menghubungkan data uji farmakologis dengan efek klinis. Yang menarik saat ini juga interaksi produk herbal dengan obat-obatan sintetis ketika kedua obat ini dimanfaatkan secara bersamaan pada pengobatan penyakit. Pemahaman yang baik tentang farmakokinetika dan bioavailability komponen aktif dalam obat herbal juga akan sangat membantu dalam perencanaan regimen dosis yang rasional (Battaram et al. 2002). 
Studi farmakokinetika direkomendasikan oleh banyak badan regulatory international seperti United Stated Food and Drug Administration (FDA) dan European Medicinal Agency (EMA) untuk dilakukan selama berbagai tahap pengembangan obat tradisional (Thelingwani et al. 2014). Farmakokinetika obat herbal menjadi suatu penelitian yang menantang karena kompleksitas sifat fisikokimia komponen dalam obat herbal serta masih sangat kurangnya metode bioanalisis yang sensitive. Kemajuan terbaru dalam instrument analisis telah menyebabkan semakin berkembangnya penelitian dalam bidang ini (Hsueh et al. 2016). Kebanyakan laporan penelitian farmakokinetika obat herbal dilakukan berdasarkan pada profil senyawa bioaktif setelah pemberian secara oral senyawa tunggal ataupun ekstrak. Revew ini diharapkan mampu memberikan informasi yang berarti untuk keperluan penelitian lanjut senyawa golongan santon ataupun sediaan yang mengandung derivate santon.

\section{METODE PENELITIAN}

\section{Profil Farmakokinetika $\alpha$-mangostin}

$\alpha$-mangostin merupakan senyawa utama derivate santon aktif pada kulit buah manggis (Garcinia .mangostana) (Mukhtaridi et al. 2017). Laporan terakhir menyatakan, ekstrak kulit buah manggis memperlihatkan berbagai aktivitas biologi menarik seperti antioksidan (Jung et al. 2006), sitotoksik (Han et al. 2009), anti inflamasi (Mohan et al. 2018), antibakteri (Suzy et al. 2018), antifungi (Kaomongkolgit et al. 2009), antivirus (Chen et al.1996) dan efek pecegahan kanker (Chin et al. 2008).

Profil farmakokinetika $\alpha$-mangostin setelah pemberian senyawa murni maupun ekstrak manggis baik secara oral maupun intra vena telah dilaporkan oleh beberapa peneliti. $\alpha$-mangostin dalam minyak jagung yang diberikan secara oral pada tikus dengan dosis $40 \mathrm{mg} / \mathrm{kgBB}$, diserap secara cepat dari saluran cerna dan mencapai konsentrasi maximum dalam plasma sebesar 4.79 ug $\mathrm{mL}^{-1}$ setelah 62.99 menit (Syamsudin et al. 2010). Penelitian yang sama melaporkan bahwa pemberian $\alpha$-mangostin dalam Poli Etilen Glikol secara oral dengan dosis $20 \mathrm{mg} / \mathrm{kgBB}$ tidak dapat ditentukan bioavailabilitasnya karena kadar obat dalam plasma yang terlalu kecil $\left(<20 \mathrm{ng} \mathrm{mL}^{-1}\right)$ sedangkan $\quad \alpha$-mangostin yang diberikan secara intra vena dengan dosis $2 \mathrm{mg} / \mathrm{kgBB}$ dengan cepat terdistribusi ke jaringan dengan $\mathrm{C}_{\max } 17.9$ ug.mL ${ }^{1}$ dan dieliminasi secara lambat dari tubuh dengan $\mathrm{T}_{1 / 2}$ adalah 3.5 jam (Li. 2011). $\alpha$ - mangostin terdistribusi hampir ke semua jaringan (hati,usus halus, ginjal,lemak, par-paru) kecuali otak setelah pemberian secara i.v maupun oral (Han et al. 2015).

Bioavailabilitas yang rendah $(\mathrm{F}=2.29 \%)$ dari $\alpha$-mangostin diduga sebagai akibat rendahnya absorpsi di saluran cerna dan metabolisme yang cepat $\alpha$ mangostin di hati dan usus halus (Han et al. 2015). Pemberian secara bersamaan $\alpha$-mangostin $20 \mathrm{mg} / \mathrm{kgBB}$ dan ( $\gamma$-mangostin) $4.5 \mathrm{mg} / \mathrm{kg} \mathrm{BB}$ ataupun senyawa golongan polifenol lainnya secara oral juga terlihat tidak mempengaruhi penyerapannya di saluran cerna (Li et al. 2013; Petiwala et al. 2014).

$\alpha$-mangostin mengalami fisrt pass efek dengan cepat melalui reaksi konjugasi dengan UDPGA transferase setelah pemberian secara oral. Metabolit yang dihasilkan dari reaksi glukoronidasi ini adalah mono dan di-glukoronat. Analisis $\alpha$-mangostin dilakukan secara LCMS/MS menggunakan kolom C18 (4.6 mm x $50 \mathrm{~mm}$ x $5 \mathrm{um}$ ) dengan fase gerak asam formiat $0.4 \%$-asetonitril system gradient dan flow rate $0.6 \mathrm{~mL} / \mathrm{menit}$. Internal standar yang digunakan adalah bergamot (Ramaiya et al. 2012).

Kehadiran senyawa santon lain tidak meningkatkan kadar plasma $\alpha$-mangostin, tetapi dapat memperlambat metabolismenya oleh enzim fase II sehingga jumlah senyawa bebas (tidak terkonjugasi) bisa ditingkatkan (Petiwala et al. 2014). Profil farmakokinetika $\alpha$-mangostin pada pemberian secara oral senyawa murni dan ekstrak mangostin yang mengandung $\gamma$-mangostin ditampilkan pada Table.1. berikut:

Suatu upaya untuk meningkatkan bioavailabilitas $\alpha$-mangostin telah dilakukan dengan pembuatan soft capsul dan penggunaan minyak sayur sebagai matrik pendispersinya. Hal ini telah memberikan kenaikan parameter $\mathrm{F} \alpha$-mangostin pada dosis $1.025,4.100$ dan $16.400 \mathrm{mg} / \mathrm{kg} \mathrm{BB}$ setelah pemberian oral pada mencit sebesar $61.1 \%, 51.5 \%$ dan 42.5\% (Zao et al. 2018)

Terdapat beberapa laporan yang membahas bioavailabilitas santon pada subjek manusia. $\alpha-$ mangostin dilaporkan mencapai kadar plasma maksimum $\left.\left(\mathrm{C}_{\max }\right)=3.12 \pm 1.47 \mathrm{ng} / \mathrm{mL}\right)$ setelah 1 jam pemberian $59 \mathrm{~mL}$ produk jus manggis yang mengandung $94.2 \mathrm{mg}$ santon pada subjek sehat. Penelitian ini memiliki keterbatasan karena sampel plasma hanya dikumpulkan selama 6 jam setelah konsumsi produk manggis dan metabolit santon juga tidak ditentukan pada penelitian ini (Orozco et al. 2013)

Laporan pengujian klinik pada manusia sehat menyatakan bahwa xanthone dari jus buah manggis ditemukan sebagai bentuk terkonjugasi setelah pemberian $(60 \mathrm{~mL})$ jus manggis (mengandung $130 \mathrm{mg}$ xanthones) dan lemak tinggi. santon bebas $(\alpha-$ dan $\gamma$ mangostin, garcinone D dan E, 8-deoxygatanin dan gartanin) terdeteksi dalam serum dan urin. Konsentrasi maksimum $\alpha$-mangostin dalam serum $(113 \pm 107 \mathrm{nmol}$ / L), dengan $\mathrm{T} \max (3,7 \pm 2,4$ jam $)$, dicatat untuk 10 subjek. Ekskresi santon dalam urin diperoleh 2\% dari dosis yang diminum (Chitchumroonchokchai et al. 2012).

\section{Profil Farmakokinetika Mangiferin}

Mangiferin, (2- $\beta$ - D-glucopyranosyl-1,3,6,7 tetrahydroxyxanthone) suatu senyawa C-glikosida santon, pada awalnya diisolasi dari Mangifera indica L 
(Anacardiaceae) (Haynes et al, 1963) dan dapat ditemukan di setidaknya enam belas keluarga tumbuhan termasuk Anacardiaceae, Iridaceae dan Gentianaceae (Sanugul et al. 2005). Sebagai senyawa glikosida santon aktif, mangiferin mendapat banyak perhatian dalam penelitian medis dan nutrisi. Mangiferin dilaporkan memiliki berbagai efek farmakologis, termasuk antioksidan (Sanchez et al. 2000), aktivitas antitumor (Shoji et al. 2011), aktivitas anti-HIV (Wang et al. 2011), immunomodulasi (Garc et al. 2003) anti-inflamasi (Duang et al. 2011) dan antidiabetes (Miura et al. 2001). Melihat potensi yang sangat baik dari senyawa mangiferin, maka telah banyak peneliti melakukan pengkajian hubungan aktivitas farmakodinamik senyawa ini terhadap profil farmakokinetikanya.

Parameter farmakokinetika dari mangiferin setelah pemberian secara oral dan intra vena mengikuti model non-kompartemen. Penelitian pada tikus yang diberikan mangiferin secara oral dan intra vena memperlihatkan bioavailabilitas yang sangat rendah pada pemberian oral yaitu $\mathrm{F}=1.2 \%$ (Han et al. 2009). Bioavailabilitas mangiferin dilaporkan lebih tinggi ketika diberikan dalam bentuk ekstrak tumbuhan Anemarhanae Rhizoma ataupun dekokta Anemarhanae Rhizoma yang mengandung mangiferin (Liu et al. 2010; Chang et al. 2018). Bioavailabilitas yang rendah dari mangiferin disebabkan oleh absorpsi yang kurang baik di saluran cerna dan juga akibat First Pass Effect (Tian et al. 2016; Gu et al. 2019). Metabolisme mangiferin melibatkan enzim fase I dan fase II secara cepat setelah pemberian secara oral. Mikroflora usus juga terlibat dalam metabolisme mangiferin menjadi aglikon aktifnya yaitu norathyriol (Liu et al. 2012).

Profil farmakokinetika mangiferin pada manusia dengan dosis $0.9 \mathrm{~g}$ memperlihatkan penyerapan yang cepat di saluran cerna, mangiferin mencapai kadar maksimum $\left(\mathrm{C}_{\max }\right) 38.64 \mathrm{ngmL}^{-1}$ setelah 1 jam pemberian secara oral. Peningkatan dosis oral tidak memperlihatkan kenaikan bioavailabiltas secara linear. Sehingga untuk meningkatkan bioavailability mangiferin perlu difikirkan bentuk sediaan yang sesuai atau merubah rute pemberian (Hou et al. 2011).

\section{Profil Farmakokinetika swertianolin, norswertianolin, belidifolin dan demetthylbelidifolin \\ Gentianella accuta Hulen adalah tumbuhan} tahunan family Gentianceae yang banyak tersebar di utara Cina, dataran tinggi Mongolia, Siberia dan timur Rusia (Wang et al. 2014). Seluruh bagian tumbuhan ini telah digunakan dalam pengobatan tradisional untuk mengobati hepatitis, sakit kuning, sakit kepala dan demam dalam pengobatan asli Mongolia (Wunir et al. 2009). Santon diketahui sebagai senyawa active utama pada G.accuta dan memperlihatkan banyak aktivitas biologi dan farmakologi.

UHPLC-MS/MS digunakan untuk penentuan dan pengujian farmakokinetika swertianolin, norswertianolin, belidifolin dan demetthylbelidifolin dalam plasma tikus setelah pemberian ekstrak $G$. accuta secara oral. Pemisahan dilakukan dengan fase diam kolom C18 (1.8um, 150mm x 2.1mm) dan fase gerak asetonitril-asam formiat $0.1 \% \quad(90: 10)$ dan butilparaben sebagai internal standar (Wang et al. 2014).

Pengujian profil farmakokinetika dilakukan setelah pemberian ekstrak G.accuta $1.0 \mathrm{~g} / \mathrm{kg}$ BB yang setara dengan $9.24 \mathrm{mg} / \mathrm{kg}$ swertianolin, $14.7 \mathrm{mg} / \mathrm{kg}$ norswertianolin, $23.9 \mathrm{mg} / \mathrm{kg}$ bellidifolin dan $17.2 \mathrm{mg} / \mathrm{kg}$ DMB. Harga parameter farmakokinetika yang ditentukan disajikan dalam Table 2. Berikut.

Dari pengujian ini terlihat bahwa ke empat senyawa xanthone mengalami proses absorpsi sangat cepat di saluran cerna dan eliminasi yang lambat setelah pemberian secara oral. Keempat metabolit memperlihatkan profil absorpsi dan distribusi yang mirip setelah pemberian ekstrak $G$. accuta, hal ini diduga sebagai manifestasi kesamaan struktur dari ke empat senyawa tersebut.

Tabel.1 Perbandingan profil farmakokinetika $\alpha$-mangostin dan $\gamma$-mangostin diberikan secara tunggal pada tikus terhadap profil farmakokinetika $\alpha$-mangostin dan $\gamma$-mangostin setelah pemberian ekstrak buah manggis

\begin{tabular}{|c|c|c|c|c|}
\hline & \multicolumn{2}{|c|}{$\alpha$-mangostin } & \multicolumn{2}{|c|}{$\gamma$-mangostin } \\
\hline & $\begin{array}{l}\text { Rata-rata senyawa } \\
\text { murni }\end{array}$ & $\begin{array}{c}\text { Rata-rata } \\
\text { extract }\end{array}$ & $\begin{array}{l}\text { Rata-rata senyawa } \\
\text { murni }\end{array}$ & $\begin{array}{l}\text { Rata-rata } \\
\text { extract }\end{array}$ \\
\hline $\begin{array}{l}\text { Cmax } \\
(\mathrm{mg} / \mathrm{kg})\end{array}$ & $40.9(3.00)$ & $58.1(2.21)$ & $147(5.55)$ & $95.1(3.20)$ \\
\hline Tmax (jam) & 1 & 2 & 1 & 2 \\
\hline $\operatorname{Ke}(1 /$ jam $)$ & $0.07(0.01)$ & $0.29(0.01)$ & $0.24(0.02)$ & $0.33(0.02)$ \\
\hline $\mathrm{t} 1 / 2(\mathrm{jam})$ & $18.5(2.25)$ & $2.51(0.08)$ & $5.33(1.01)$ & $2.49(0.14)$ \\
\hline MRT (jam) & $22.3(2.98)$ & $4.28(0.09)$ & $5.53(0.89)$ & $4.47(0.15)$ \\
\hline AUC $0-\infty$ & $240(24.2)$ & $240(7.47)$ & $471(15.9)$ & $452(5.6)$ \\
\hline \multicolumn{5}{|l|}{$\mathrm{h} / \mathrm{mL}) /$ Dose $(\mathrm{mg} / \mathrm{kg})$} \\
\hline $\mathrm{Vz}(\mathrm{L} / \mathrm{kg})$ & $128(17.4)$ & $15.8(0.77)$ & $15.6(2.58)$ & $7.84(0.40)$ \\
\hline Vss $(\mathrm{L} / \mathrm{kg})$ & $85.0(9.65)$ & $16.1(0.52)$ & $10.6(1.11)$ & $8.09(0.26)$ \\
\hline $\mathrm{CL}(\mathrm{L} / \mathrm{h} / \mathrm{kg})$ & $4.45(0.36)$ & $4.32(0.12)$ & $2.22(0.09)$ & $2.23(0.03)$ \\
\hline
\end{tabular}


Jurnal Penelitian Farmasi Indonesia 8(2), Desember 2019

ISSN 2302-187X e-ISSN 2656-3614

Tabel 2. Profil Farmakokinetika swertianolin, norswertianolin, belidifolin dan demetthylbelidifolin setelah pemberian ekstrak terstandar G. accuta pada tikus secara oral(n=12)

\begin{tabular}{|c|c|c|c|c|c|}
\hline \multirow{2}{*}{$\begin{array}{l}\text { Parameter } \\
\text { diuji }\end{array}$} & \multirow[t]{2}{*}{ yang } & \multicolumn{4}{|c|}{ Senyawa } \\
\hline & & Swertianolin & Norswertianolin & Belidifolin & DMB \\
\hline $\mathrm{C} \max (\mathrm{ng} / \mathrm{mL}$ & & $196.8 \pm 22.0$ & $340.2 \pm 35.6$ & $536.5 \pm 29.1$ & $603 \pm 28.7$ \\
\hline $\mathrm{T} \max (\mathrm{jam})$ & & $0.40 \pm 0.12$ & $0.27 \pm 0.07$ & $1.00 \pm 0.18$ & $0.94 \pm 0.15$ \\
\hline $\mathrm{T} 1 / 2$ (jam) & & $19.7 \pm 9.64$ & $11.3 \pm 4.51$ & $19.9 \pm 8.11$ & $24.9 \pm 8.19$ \\
\hline $\begin{array}{l}\text { AUC0-t } \\
\text { jam/Ml }\end{array}$ & (ng & $545.2 \pm 92.6$ & $971.7 \pm 216.90$ & $1066.4 \pm 130.1$ & $1206 \pm 226.3$ \\
\hline $\begin{array}{l}\mathrm{AUC0}-\sim \\
\mathrm{jam} / \mathrm{mL})\end{array}$ & (ng & $903.2 \pm 145.7$ & $1179.5 \pm 211.1$ & $1679.6 \pm 373.0$ & $2001.1 \pm 392.8$ \\
\hline
\end{tabular}

\section{SIMPULAN}

Profil farmakokinetika senyawa aktif dari sediaan herbal golongan santon pada umumnya memperlihatkan adsorpsi yang cepat setelah pemberian secara oral di saluran cerna. Absorpsi yang kurang baik di saluran cerna dan metabolisme yang cepat menjadi penyebab rendahnya bioavailability senyawa santon di dalam tubuh. Adanya kecenderungan senyawa mengalami First Pass Effect dapat menjadi suatu pertimbangan dalam merencanakan bentuk sediaan dan rute pemberian. Revew profil farmakokinetika komponen santon aktif dalam sediaan herbal ini diharapkan dapat membantu menjustifikasi nilai terapi, dan klinis sediaan herbal dengan komoponen bioaktiv golongan santon, serta menjadi acuan dalam perencanaan dosis.

\section{DAFTAR PUSTAKA}

Akao. Y, Nakagawa. Y, IImuna. M, Nozawa.Y. 2008. Anti-Cancer Effects of Xanthones from Pericarps of Mangosteen Int $\mathrm{J}$ Mol Sci. 2008 Mar; 9(3): 355-370

Bhattaram. V.A, Graefe. U, Kohlert. C, Veit. M and Derendorf. H. 2002. Pharmacokinetics and bioavailability of herbal medicinal products. Phytomedicine. 9 Suppl 3:1-33.

Bennett. J.G and Hiok-Huang Lee. 1989. Xanthones From Guttiferae. Phytochemwy.28 (4) 967-998

Chang. H.Y, Thomas.Y.H dan Tung. H.T. 2018. Monitoring of polyphenol mangiferin by Liquid Chromatography tandem mass Spectrometry in Rat and its comparative Pharmacokinetic Study of a Single Compound, a single botanic extract and multiple Botanic Extract. Sep Sci plus. 18 (1). 603-618

Chairungsrilerd. N, Furukawa.K, Ohta.T, Nozoe. S and Ohizumi.Y. 1996. Histaminergic and serotonergic receptor blocking substances from The Medicinal plant Garcinia mangostana. Planta Med. 62. 471-472

Chen. S.X, Wan. M and Loh. B.N. 1996. Active constituents against HIV-1 Protease from Garcinia mangostana. Planta Med. 62. 381-382

Chin. Y.W, Jung. H.A, Chai. H, Keller. W.J and Kinghorn. A.D 2008. Xanthones with quino ne Reductase-inducing Activity from The Fruit of Garcinia mangostana (Mangosteen). Phytochemistry. 69. 754-758

Chitchumroonchokchai. C, Riedl. K.M, Suksumran. S, Clinton. S.K, Kinghorn. A.D and Faila.M.L. 2012. Xanthones in mangosteen juice are absorbed and partially conjugated by healty adults. J Nutr. 142. 675-680

Dachriyanus, Lia Sartika, M. Kesuma, M.H.Mukhtar, 2006, Efek Senyawa Rubraxanthone terhadap Kadar Kolesterol Total,
Trigliserida, HDL dan LDL Dalam Mencit Putih Jantan. Jurnal Sains dan Teknologi Farmasi 11(1), 12-15

Dharmaratne. H.R.W, Yoshikazu. S, Piyasena. K.G.P, and Vasanthi. T. 2013. Antibacterial activity of xanthones from Garcinia mangostana (L.) and their structure-activity relationship studies. Natural Product Research: Formerly Natural Product Letters. 27 (10). 938-941

Duang. X.Y, Wang. W, Zhou. X.D and Huang. D.M (2011) Mangiferin; a possible strategy for periondontal disease to therapy. Med Hypotheses. 76; 486-488

Ee. G.C.L, Siow. H.T, Mawardi. R, Chang. K.L, Yang. M.L and Rusea.G. 2011. Artomandin, a new xanthone from Artocarpus kemando (Moraceae).Naturale product Research 25. (10) 955-1003

Ganogpichayagrai A, Palanuvej C, Ruangrungsi N. 2017. Antidiabetic and anticancer activities of Mangifera indica cv. Okrong leaves. J Adv Pharm Technol Res 8:19-24

Ghosal S, Chaudhuri RK, Nath A.1973. Chemical constituents of gentianaceae. IV. New xanthones of Canscora decussata. $J$ Pharm Sci. ;62(1):137-9.

Gutierrez-Orozco, F. and Failla, M. L. 2013 'Biological activities and bioavailability of mangosteen xanthones: A critical review of the current evidence', Nutrients, 5(8), pp. 31633183.

Gu. P.C, Wang. L, Han. M.N, Peng. J, Shang. J.C, Pan. Y.Q. dan Han. W.L. 2019. Comparative Pharmacokinetic Study of Mangiferin in Normal and Alloxan-Induced Diabetic Rats after Oral and Intravenous Administration by UPLCMS/MS. Pharmacology. 103. 30-37

Han. D, Chengjun.C, Cong.Z, Yu.Z and Xing.T. 2009 Determination of Mangiferin in Rat plasma by liquid-liquid extraction With UPLC-MS/MS. J.Pharm and Biom Analysis. 51. 260-263

Han. A.R, Kim. J.A, Lantvit. D.D, Kardono. L.B. 2009. Cytotoxic xanthone constituents of The Stem Bark of Garcinia mangostana (mangosteen). J Nat Prod. 72. 2028-2031

Han. S.Y, Byoung. H.Y, Yu. C.K, YoME Properties and Tentative Identification of Metabolites of $\alpha$-mangostin from Garcinia mangostana in Mice by Automated Microsampling and UPLC-MS/MS Metods. Plos one. 10 (7); e0131587.doi; 10.1371

Haynes, L. J. 1963. Naturally occurring C-glycosyl compounds. Advances in Carbohydrate Chemistry, 18, 227-258.

Hou, S., Wang, F., Li, Y., Li, Y., Wang, M., Sun, D., \& Sun, C. (2012). Pharmacokinetic study of mangiferin in human plasma after oral administration. Food Chemistry, 132(1), 289-294. 
Hu. Q.F, Xiao. L.W, Wan. L.Z, Jin.W, Yong. X, Hai. T.H, Jing. L, Xin.L, Guang. Y.Y and Xue. M. L. 2019. Two New Xanthones from Comastoma pulmonarium and Their AntiTobacco Mosaic Virus Activity. Chemistry of Natural Compounds 6. 896-898

Hsueh. T.P, Wan. L.L and Tung. H.T. 2016. Pharmacokinetic Interactions of Herbal Medicines for The Treatment of Chronic Hepatitis. Journal of Food and Drug Analysis. 30. $1-10$

Iimuna M, Tosa H, Tanaka T, Asai F, Kobayasi Y, Shimano R, 1996, Antibacterial Activity of xanthones from Guttiferous Plants Against Methicilin Resistant Staphylococus aureus, $J$ Pharm. Pharmacol 48: 861-865

Jantan, I., Pisar, M.M., Idris, M.S., Taher, M., Ali, R.M., 2002. In vitro Inhibitory Effect of Rubraxanthone Isolated from Garcinia parvifolia on Platelet Activating Factor Receptor Binding, Planta Med 68: 1133-1134

Jiang. D.J, Dai. Z. and Li. Y. J. 2004. Pharmacological effects of xanthones as cardiovascular protective agents, Cardiovasc. Ther. 22, 91-102.

Jung. H.A, Su. B.N, Keller. W.J, Mehta. R.G and Kinghorn. A.D. 2006. Antioxidant xanthones from The Pericarp of garcinia mangostana (Mangosteen). J.Agric. Food Chem. 54. 20772082

Kaomongkolgit. R, Kusuma. J and Niratcha.C. 2009. Antifungal activity of Alpha Mangostin Against Candida albicans. Journal of Oral science. 51 (3) 401-406.

Kondo, M. I. K. 2009 Bioavailability and Antioxidant Effects of a Xanthone-Rich Mangosteen (Garcinia mangostana) Product in Humans', (59 mL), pp. 8788-8792. doi: $10.1021 / \mathrm{j} 901012 \mathrm{f}$

Liu. Y, Fuping. X, Xing. Z, Liu. Y, Yuanhui. D, Zhifeng. W, Yi. F and Xiong. L. 2010. Application of a liquid chromatography/ tandem mass spectrometry method to Pharmacokinetic study of mangiferin in rats.

Liu. H, Bin. W, Guoya. P, Lei. H, Zhixiong. L, Mingsong. F, Longhai. J, Minchang. C, Ke. W and Chengang. H Metabolism and Pharmacokinetics of Mangiferin in Conventional Rats, Pseudo-Germ-Free Rats, and Streptozotocin-Induced Diabetic Rats. Drug Metabolism and Dispotition. 40 (11). 2109-2118

Li.L, Isabelle.B, Ah-Reum. H, Matthias. H, Alan. D. K, Reginald. F dan Veronika. B. 2011. Pharmacokinetics of a-mangostin in rats after intravenous and oral application. Mol. Nutr. Food Res. 55 (1), S67-S74

Li.L, Ah Reum. H, Douglas. K, Reginald. F..F, Hartmurt. D and Veronica. B, 2013, Pharmacokinetic Properties of Pure Xanthones in Comparison to a Mangosteen Fruit Extract in Rats. Planta Med. 79; 646-653

Mazimba. O, Frederic. N, Victor. K and Grija.S.S. 2013. Xanthones and Anthranoids from the Medicinal Plants of Africa Medicinal Plant Research in Africa, 393-434.

Miura.T, Hiroyukilchiki, Itsuko. H, Naokilwamoto, Motoshikao, Masayoshi. K, Erikolshihara, Yasuhiro. K. Minoru.O, Toraolshida and Keichiro. T, 2001. Antidiabetic activity of a xanthone compound, mangiferin. Phytomedicine. 8 (2) 85 87

Mohan. S, Suvita.S, Siddig I.A, Neelaveni.T. 2018. Antiinflammatory molecular mechanism of action of $\alpha$ Mangostin, the major xanthone from the pericarp of Garcinia mangostana; an in silico, in vitro and in vivo approach. Food and Fuction. 9 (7) 3860-3871

Morais. T.C, , Synara. C. L, Karine. M. M. B. C, Bruno. R. A, Francisco. T. C. D. S, Maria, T.S.T, Vietla. S. R, and Flávia. A. S. 2012. Mangiferin, a natural xanthone, accelerates gastrointestinal transit in mice involving cholinergic mechanism. World J Gastroenterol. 18(25): 3207-3214.

Muchtaridi. M, Nadia. A.P, Tianan. M and Ida.M. 2017. Validation Analysis Methods of $\alpha$-Mangostin, $\gamma$-Mangostin and Gartanin Mixture in Mangosteen (Garcinia mangostana L.) Fruit Rind Extract from West Java with HPLC. $J$ App Pharm Sci. 7(10) 125-130

Nelli. G. B, Anand. S. K and Eswar. K.K. 2013. Antidiabetic effect of $\alpha$-mangostin and its protective role in sexual dysfunction of streptozotocin induced diabetic male rats. Systems Biology in Reproductive Medicine. 59: 319-328

Orozco. F.G and Failla. M.L. 2013. Biological Activities and Bioavailability of Mangosteen Xanthones: A Critical Review of the Current Evidence. Nutrients. 5, 3163-3183

Petiwala. S.M, Gongbo. L, Atulkumar. R, Anoop. K, Ravinder. K. G, Seema. S and Jeremy. J.J. 2014. Pharmacokinetic Characterization of Mangosteen (Garcinia mangostana) Fruit Extract Standardized to $\alpha$-mangostin in $\mathrm{C} 57 \mathrm{BL} / 6$ Mice. Nutrition Research. 34. 336-345

Ramaiya. A, Gongbo Li, Sakina M, Petiwala and Jeremy J. J. 2012, Single Dose Oral Pharmacokinetic Profile of $\alpha$-mangostin in Mice. Current Drug Targets. 13;1698-1704

Sanugul, K., Akao, T., Li, Y., Kakiuchi, N., Nakamura, N., \& Hattori, M. 2005. Isolation of a human intestinal bacterium that transforms mangiferin to norathyriol and inducibility of the enzyme that cleaves a C-glucosyl bond. Biological \& Pharmaceutical Bulletin, 28(9), 1672-1678

Sanchez, G. M., Re, L., Giuliani, A., Nunez-Selles, A. J., Davison, G. P., \& LeonFernandez, O. S. (2000). Protective effects of Mangifera indica L. extract, mangiferin and selected antioxidants against TPA-induced biomolecules oxidation and peritoneal macrophage activation in mice. Pharmacological Research, 42(6), 565-573.

Shan. T, Ma.Q, Guo.K, Liu.J, Li.W, Wang.F and wu.E. 2011. Xanthones from Mangosteen Extracts as Natural Chemopreventive Agents: Potential Anticancer Drugs. Curr Mol Med. 11(8): 666-677.

Shoji. K, Tsubaki. M, Yamzoe. Y, Satou.T and Itoh.Y. 2011 Mangiferin induces apoptosis by suppressing $\mathrm{Bcl}-\mathrm{xL}$ and XIAP expressions and nuclear entry of NF-kB in HL60cells. Arch Pharm Resi.34; 469-475

Sriyatep. T, Ittipo. S, Wisanu.M, Acharavadee. R, Thunwadee.R, Raymond. J.A and Surat. L. 2015. Bioactive Prenylated Xanthones from the Young Fruits and Flowers of Garcinia cowa J. Nat. Prod. 2015, 78, 2, 265-271

Suzy. S.A , Herawati. M, Dewi. W and Supratman. U. 2018. Antibacterial Activity of Prenylated Xanthones from Pericarp of Garcinia mangostana against Persistent Dental Infection Microorganism Enterococcus faecalis. Research Journal of Chemistry and Environment. 22 (2) 184-188

Syamsudin, Faizatun and Lestari. R. 2010. HPLC Analysis Mangostin After Orally Administration in Rats. Asian Journal of Chemistry. 22 (9) 6729-6733

Talamond. P, Laurence. M, Annick. G, Alexandre. D.K, Serge. H, Alain. F and Claudine. C. 2008. First report on mangiferin (C-glucosyl-xanthone) isolated from leaves of a wild coffee plant, Coffea pseudozanguebariae (Rubiaceae). Acta Bot. Gallica, 155 (4), 513-519.

Tewtrakul. S, Wattanapiromsakul. C, and Mahabusarakam. W. 2009. Effects of compounds from Garcinia mangostana on inflammatory mediators in RAW264. 7 macrophage cells. J. Ethnopharmacol. 121, 379-382.

Thelingwani. R and Masimirembwa. C. 2014. Evaluation of Herbal Medicines: Value Addition to Traditional Medicines Through Metabolism, Pharmacokinetic and Safety Studies. Curr Drug Metab. 2014;15(10):942-52. 
Tizziani. I, Marcos.P, Dalila. V, Fabiana C.M, Ana P.R Daiane.F.M, Moacir. G.P, Gustavo. A. M and Ines.M.C.B. 2018. A new xanthone as a chemical marker of four Polygala species (Polygalaceae). Biochemical Systematics and Ecology. 78, 46-48

Trinh. T.D.B, Quach, Bui. T.T.T, Bui. D.N, Stærk. D, Nguyen. L.H.D and Jäger. A.K 2017, 'Xanthones from the twigs of Garcinia oblongifolia and their antidiabetic activity', Fitoterapia, vol. 118, pp. 126-131.

Victor. K, Louis. P.S, Judith. L.N,O, Hugues. F, Benjamin. W and Thomas. E. 2014. Cytotoxicity and modes of action of three naturally occurring xanthones (8-hydroxycudraxanthone G, morusignin I and cudraxanthone I) against sensitive and multidrug-resistant cancer cell lines. Phytomedicine. 21:315-322.

Wahyuni F.S, Khozirah. S, Johnson S, Nordin H.L, Dachriyanus, 2015. Cytotoxic xanthones from the stembark of Garcinia cowa Roxb. Journal of chemical of Pharmaceutical Research. 7(1) 227-236

Wang. R.R, Gao. Y.D, Ma. C.H, Zhang. X.J and Huang. C.G. 2011. Mangiferin an anti-HIV-1 agent targeting protease and effective against resistant stains. Molecules. 16; 4264-4277
Wang. Z, Qiong. W, Ying. Y, Chunjuan. Y, Hai. J, Qiuhong. W, Bingyou. Y and Haixue. K. 2015. Determination and Pharmacokinetic Study of four xanthones in rat plasma after oral administration of Gentianella acuta extract by UHPLCESI-MS/MS. Journal of Ethnopharmacology. http;//dx.doi.org/10.1016/j.jep.2015.08.023

Yoo. H, Ku. S.K, Lee. W, Kwak. S, Baek. Y.D, Min. B.W, Jeong. G.S, Bae. J.S. 2014. Antiplatelet, anticoagulant, and profibrinolytic activities of cudratricusxanthone A. Arch Pharm Res. 37(8):1069-78.

Zhao. Y, Guosheng. T, Qiang. T, Jing. Z, Yingying. H, Enbo. C, Shuangli. L, Daihong.L, Lianxeu. Z and Shijie. W. 2018 A Method of Effectively Improved a-Mangostin Bioavailability.J Drug Metab Pharmacokinet. 41(5) 605613

Zhengxiang. X, Hong. Z, Danqing. X, Yuanzhi. L, Wenwei. F, Hongsheng. T, Peng. C, Ling. Y and Hongxi. X. 2015. Xanthones from the leaves of Garcinia cowa induce cell cycle arrest, apoptosis and autophagy in cancer cells. Molecules. 20:11387-11399 